observed in the centres of the (0001) faces of these crystals. When these layers are complete over the length of the crystal edge, the hexagonal type of growth spirals is obtained as shown in Figs. 1 and 2.

A complete description of the observations and techniques used will be reported elsewhere.

Horizons Incorporated,

M. A. SteinberG

Cleveland, Ohio.

Sept. 18.

${ }^{1}$ Burton, W. K., Cabrera, N., and Frank, F. C., Nature, 163, 398 (1949); Discuss. Farad. Soc., No. $5,33,73$ and (1952).

- Griffin, L. J., Phil. Mag. 42, 775 and 1337 (1951).

${ }^{3}$ Amelinckx. S., Grosjean, C., and Dekeyser, W., C.R. Acad. Sci. Paris, 234, 113 (1952). Amelinckx, S., Phil. Mag., 43, 562 (1952). ‘ Forty, A. J., Phil. Mag., 43, 481 (1952).

'Tolansky, S., and Omar, M., Nature, 170, 81 (1952).

Straumanis, M. phys. Chem., B, 19, 63 (1932); B, 28. 246 (1934) B, 30, 132 (1935).

\section{Mechanism of Fracture of Concrete}

H. J. CowaN's ${ }^{1}$ hypotheses for the fracture of concrete are very similar to those already proposed by Prof. M. Roš ${ }^{2}$. Such hypotheses usually rely mainly on the observations of failing loads of specimens for their justification, and proceed from the assumption that concrete may be regarded as a homogeneous isotropic material. In the Division of Building Research of the Commonwealth Scientific and Industrial Research Organization, an extensive experimental study has been made of the strain distribution in various types of concrete specimen, using one concrete mix throughout. The results suggest that in all specimens the first failures occur when the tensile strain is about $10^{-4}$. In compression tests of cylinders, this strain occurs when the load is about fifty per cent of the ultimate, and in unreinforced flexural specimens at about ninety per cent of the ultimate. The measurements made here also show how widely the concrete strains may vary in a region in which they are theoretically uniform.

These results concerning maximum tensile strain and the development of tensile cracks in specimens before the maximum load is reached are confirmed by other workers ${ }^{3-5}$. Our tests suggest that a noticeable decrease in the gradient of the compressive stress-strain curve coincides with the formation of tensile cracks on the circumference of a cylindrical compression specimen. I believe that the so-called shear failure is a secondary development which occurs after the vertical splitting has begun. It may be of interest to note that Wästlund ${ }^{6}$ claims to have shown that the plane of so-called shear failure in compression specimens is actually a plane perpendicular to the maximum tensile stresses.

In the accompanying graph the ratio of the stress at fracture to the uniaxial tensile strength is plotted for various hypotheses of failure for a range of stresses from $f_{x}=-f_{y}$ to $f_{y}=-f_{x}$. The hypotheses chosen are maximum normal stress (straight broken lines), maximum normal strain (straight full lines) and maximum total strain energy per unit volume (curved full lines). It is desired to show the extent to which the limit provided by each hypothesis may vary according to the value assumed for Poisson's ratio. In this graph the extremes for $\nu=0$ and $\nu=0.5$ are shown (the maximum strain theory with $v=0$ coincides with the maximum stress theory). These are undoubtedly extremes, but such values have been proposed for concrete under certain conditions ${ }^{4, ?}$.

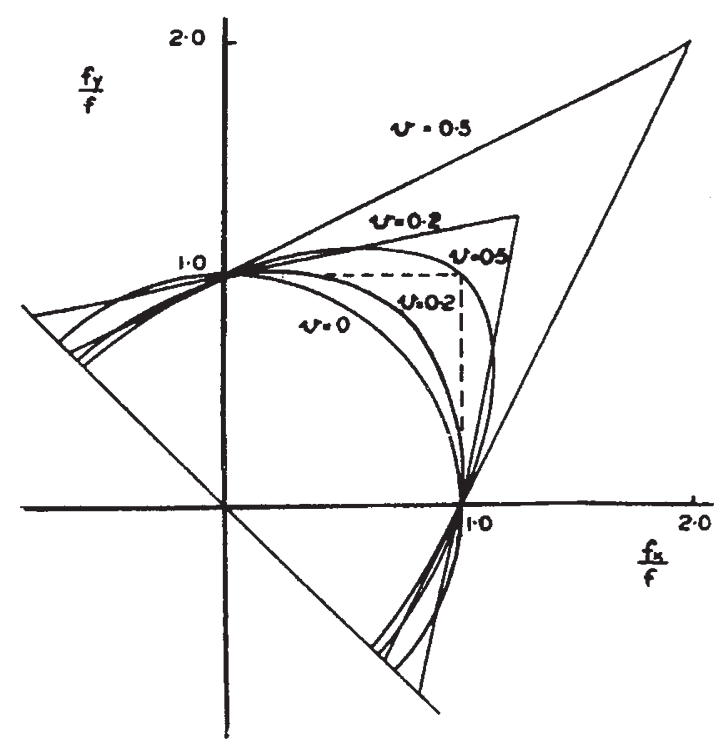

Since Poisson's ratio itself may vary widely for one mix, and in the range of values most commonly accepted $(0 \cdot 1<v<0 \cdot 25)$ the limiting curves for all hypotheses lie close together, the difficulty of choosing any one hypothesis, principally on an observation of the loads and hence the stresses, during the test becomes obvious. A complete set of strain measurements for the effective part of the test specimen is also essential.

Division of Building Research,

Frank A. Blakey

Commonwealth Scientific and

Industrial Research Organization,

Melbourne. Sept. 22.

${ }^{1}$ Cowan, H. J., Nature, 169, 663 (1952).

${ }^{2}$ Roš, M. Die Bruchgefahr fester Körper. K.M.P.A. (Zurich), Bericht Nr. 172 (1949).

3 Jones, R. H., Brit. J. App. Phys., 3, 229 (1952).

- Berg, O. Ya, Dokl. Akad. Nauk. SSSR., 70, 617 (1950).

$\checkmark$ Richart, F. E., Brandtzaeg, A., and Brown, R. L., Univ, Illinois Eng. Exp. Sta. Bull. No. 185 (1928).

- Wästlund, G., Betong, (3), 135 (1934).

"Glanville, W. H., and Thomas, H. G., Building Research Tech. Paper No. 21 (1939).

\section{Enhancement of Auroral Hydrogen Lines towards Lower Latitudes}

MANy years ago, I suggested that the bundles of solar electric rays which produce the auroræ and most magnetic disturbances are composed of electrons electrostatically neutralized by positive ions of great specific charge, mainly protons ${ }^{1-4}$.

On this view the current density $(i)$ of a bundle composed of electrons and protons is given by

$$
i=n e\left(V_{e}-V_{p}\right) \text {, }
$$

where $n$ is the number of electrons or protons in unit volume, and $V_{e}$ and $V_{p}$ are the velocities of the electrons and protons respectively.

The number of electrons $v_{e}$ and protons $\nu_{p}$ entering unit cross-section perpendicular to the direction of the current in unit time is $v_{e}=n V_{e}$, and $v_{p}=n V_{p}$. Thus the velocity of the protons $\left(V_{p}\right)$ relative to that of the electrons $\left(V_{e}\right)$ essentially determines the relative intensity of the hydrogen lines in the auroral luminescence. 